\title{
Utilization of Taguchi Approach to Investigate the Effects of Cutting Parameters on Surface Finish of AISI 1020 Steel while turning
}

\author{
Mandeep Singh $^{{ }^{*}}$ and Ashwani Kumar ${ }^{\dagger}$ \\ †Department of Mechanical Engineering, SSGI, Pathankot India-145001 \\ Received 25 Nov 2017, Accepted 26 Jan 2018, Available online 12 Feb 2018, Vol.8, No.1 (Jan/Feb 2018)
}

\begin{abstract}
To judge the success of a machining operation, surface finish of the machined parts is one of the important criteria. The value of optimum machining parameters (for better surface finish) can be either decided on the basis of a large number of experimental trails or design of experiments (DoE) can be used to predict the same with significantly lesser number of experimental trails. The aim of this work was to reveal the application of Taguchi method to study the effect of the machining/cutting parameters for surface finish during turning of AISI 1020 steel under different cutting environments. The results revealed that spindle speed was the most influential factor which affected surface roughness in dry turning as well as wet turning. However, depth of cut was second influential factor in dry turning but feed rate was more influential than depth of cut during wet turning.
\end{abstract}

Keywords: Machining, Turning, Steel, Surface finish, Taguchi, Minitab, Anova.

\section{Introduction}

Machining is one of the mostly used manufacturing process to get acceptable dimension in tolerance zone, good surface finish as well as requisite complex geometry [Abhang \& Hameedullah, 2014]. Turning is the most frequently utilized method for machining [Dornfeld \& Helu, 2007]. To get the required geometry and surface characteristics on turned job, some parameters must be tuned accordingly. These parameters are: primary (cutting speed/spindle speed, feed rate and depth of cut) and secondary (cutting environment, cutting fluid, tool nose radius etc.) [Juneja et al., 2003]. By adjusting these parameters, required surface finish can be obtained. Surface finish of the machined parts is a critical criterion by which machining performance is judged [Azam et al., 2015]. A better surface finish can prevent premature fatigue failure, improve corrosion resistance, reduce friction, wear, and noises thus ultimately improves the product life [Khan et al., 2009]. Various studies had been conducted on several materials which investigated the effect of different cutting parameters on surface finish of turned specimen [Suresh et al., 2012; Ciftci et al.' 2006; Debnath et al.; 2016; Dhiman et al.; 2008]. These studies suggested that for different materials, different factors were significantly affected surface finish. However, these studies were either conducted in dry cutting environment or wet cutting environment [Patel

*Corresponding author's ORCID ID: 0000-0002-5002-0363 DOI: https://doi.org/10.14741/ijcet.v8i01.10896
\& Panchal, 2014]. Rarely, a study was conducted with similar kind of parameters in dry as well as wet environment simultaneously. Especially, the results of the effect of cutting parameters on the surface roughness of AISI 1020 steel are still to be established. So in this study, AISI 1020 steel was turned with HSS tool with similar cutting parameters in dry as well as wet environment to study their effect on surface finish. Two types of cutting fluids were also investigated: straight cutting fluid (mineral oil) and water based cutting fluid.

\section{Materials and Methods}

The conventional lathe machine (Kirloskar, India) was used for turning of AISI 1020 steel by using HSS Mseries tool (Trident Tools Pvt. Ltd, India). Turning process was carried out in three different cutting environments: dry, wet turning with water based cutting fluid (water: cutting fluid $=25: 1$ ) and wet turning with mineral oil as cutting fluid. The two types of cutting fluids used in this study i.e. straight cutting oil and water based cutting fluid having flash point $226{ }^{\circ} \mathrm{C}$ and $160{ }^{\circ} \mathrm{C}$, respectively . The cutting parameters and their factor levels considered in this study are shown in table 1 . The experimental layout was based on the L9 orthogonal array and is shown in table 2. For each experimental run, five different workpieces were turned and average value of surface roughness (Ra) is reported in this work. Surface roughness was determined through a contact type profilometer (Mitutoyo Surfacetest SJ-400). MINITAB 
17 software was utilised for the statistical analysis of response data, which included Taguchi ( $\mathrm{S} / \mathrm{N}$ ratio) analysis and analysis of variance (ANOVA).

Table 1 Factor levels of cutting parameters

\begin{tabular}{|c|c|}
\hline Control factor & Value at different levels \\
\hline Spindle speed (RPM) & L1 $=250, \mathrm{~L} 2=350, \mathrm{~L} 3=450$ \\
\hline Feed rate $(\mathrm{mm} / \mathrm{rev})$ & $\mathrm{L} 1=0.20, \mathrm{~L} 2=0.25, \mathrm{~L} 3=0.30$ \\
\hline Depth of cut $(\mathrm{mm})$ & $\mathrm{L} 1=0.3, \mathrm{~L} 2=0.5, \mathrm{~L} 3=0.7$ \\
\hline
\end{tabular}

Table 2 L9 Orthogonal array for experiment

\begin{tabular}{|c|c|c|c|}
\hline Run & $\begin{array}{c}\text { Cutting } \\
\text { speed }\end{array}$ & $\begin{array}{c}\text { Feed } \\
\text { rate }\end{array}$ & $\begin{array}{c}\text { Depth of } \\
\text { cut }\end{array}$ \\
\hline 1 & L1 & L1 & L1 \\
\hline 2 & L1 & L2 & L2 \\
\hline 3 & L1 & L3 & L3 \\
\hline 4 & L2 & L1 & L2 \\
\hline 5 & L2 & L2 & L3 \\
\hline 6 & L2 & L3 & L1 \\
\hline 7 & L3 & L1 & L3 \\
\hline 8 & L3 & L2 & L1 \\
\hline 9 & L3 & L3 & L2 \\
\hline
\end{tabular}

\section{Results and Discussion}

\subsection{Dry Turning}

The value of surface roughness and corresponding S/N ratio is mentioned in table 3 . As per orthogonal experimental design, it is possible to differentiate the effect of each cutting parameter at different level. For example, the mean $\mathrm{S} / \mathrm{N}$ ratio for the spindle speed at levels 1,2 and 3 can be calculated by averaging the $\mathrm{S} / \mathrm{N}$ ratios for the experiments 1-3, 4-6, and 7-9, respectively. The mean $\mathrm{S} / \mathrm{N}$ ratio for each level of the cutting parameters is summarized and called the mean $\mathrm{S} / \mathrm{N}$ response table for that specific parameter. The mean $\mathrm{S} / \mathrm{N}$ response table for surface roughness is as table 4.

Table $3 \mathrm{R}_{\mathrm{a}}$ and $\mathrm{S} / \mathrm{N}$ ratio values for dry turning

\begin{tabular}{|c|c|c|}
\hline Run & $\mathrm{R}_{\mathrm{a}}(\mu \mathrm{m})$ & S/N Ratio \\
\hline 1 & 5.20 & -14.32 \\
\hline 2 & 5.60 & -14.96 \\
\hline 3 & 6.01 & -15.57 \\
\hline 4 & 4.48 & -13.02 \\
\hline 5 & 4.94 & -13.87 \\
\hline 6 & 4.50 & -13.06 \\
\hline 7 & 4.56 & -13.17 \\
\hline 8 & 4.32 & -12.70 \\
\hline 9 & 4.78 & -13.58 \\
\hline
\end{tabular}

Table 4 Mean $\mathrm{S} / \mathrm{N}$ response table for surface roughness for dry turning

\begin{tabular}{|c|c|c|c|}
\hline Level & Spindle speed & Feed rate & Depth of cut \\
\hline 1 & -14.95 & -13.51 & -13.36 \\
\hline 2 & -13.32 & -13.85 & -13.86 \\
\hline 3 & -13.16 & -14.08 & -14.21 \\
\hline Delta & 1.79 & 0.57 & 0.85 \\
\hline Rank & 1 & 3 & 2 \\
\hline
\end{tabular}

In the table 4, value of 'Delta' reveals the difference in highest and lowest mean response of levels for the corresponding cutting parameter. 'Rank' describes the relative influence of cutting parameter on response. So from table 4 it is observed that spindle speed had greatest influence on surface roughness followed by depth of cut and feed rate. The main effect plot for surface roughness is given in figure 1 . In the plots, $x-$ axis indicates the value of each cutting parameter at three level and $y$-axis indicates the response value. Optimal factor settings for optimum response are obtained through the main effects plot. In Taguchi analysis, optimum response is obtained by maximizing $\mathrm{S} / \mathrm{N}$ ratio. Figure 1 shows that to reduce level of surface roughness, spindle speed should be set to its highest level, feed rate and depth of cut to their lowest level.

General Linear Model (GLM) was used in analysis of variance (ANOVA) of surface roughness. In ANOVA, the 95\% confidence level was chosen to determine the factors effect on the surface roughness. Table 5 shows the results of ANOVA for surface roughness. Factors having 'p-value' less than 0.05 are significant. The percentage contribution of each factor is represented by corresponding ' $\% \mathrm{C}$ ' value.

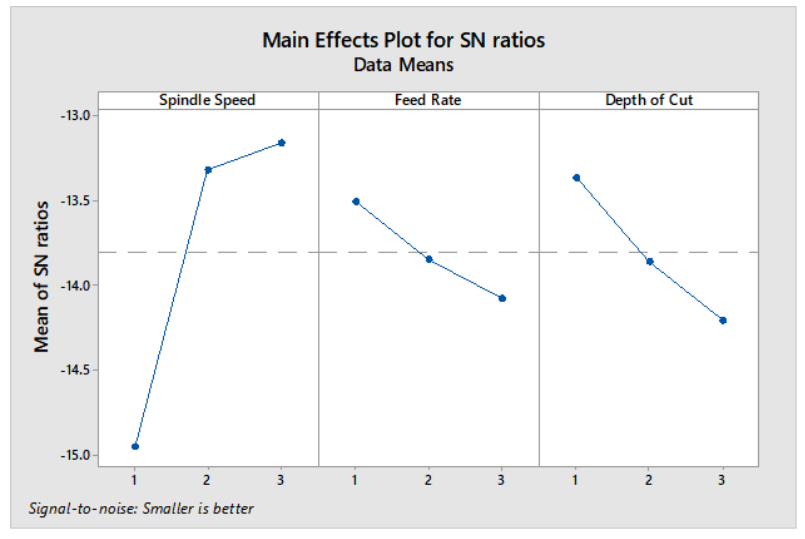

Fig. 1 The main effects plot for $S / N$ ratios of surface roughness for dry turning

Table 5 confirmed that spindle speed was the most significant factor which effected surface roughness having percentage contribution up to $78.18 \%$. After that second influencing factor was depth of cut having percentage contribution up to $12.35 \%$ followed by feed rate having percentage contribution up to $5.12 \%$. It is the same order of significance for the cutting parameters on surface roughness, which was observed in table table 4 . The regression equation generated through the analysis is written as equation 1.

Surface roughness $=4.844-0.442$ Spindle Speed + 0.223 Feed Rate - 0.032 Depth of Cut

Table 5 ANOVA table for surface roughness for dry turning

\begin{tabular}{|c|c|c|c|c|}
\hline Source & DoF & Adj SS & p-value & $\% \mathrm{C}$ \\
\hline Spindle speed & 2 & 2.03 & 0.006 & 78.18 \\
\hline Feed rate & 2 & 0.18 & 0.058 & 5.12 \\
\hline Depth of cut & 2 & 0.37 & 0.030 & 12.35 \\
\hline Error & 2 & 0.01 & - & 4.35 \\
\hline Total & 8 & 2.60 & - & - \\
\hline
\end{tabular}




\subsection{Wet turning with water based Cutting fluid}

The value of surface roughness and corresponding $\mathrm{S} / \mathrm{N}$ ratio and the mean $\mathrm{S} / \mathrm{N}$ response table for surface roughness are mentioned in table 6 and table 7 , respectively. From the table 7 , it is observed that spindle speed had highest impact on surface roughness and Feed rate was the second influencing factor followed by depth of cut.

Table $6 R_{a}$ and $S / N$ ratio values for wet turning with water based fluid

\begin{tabular}{|c|c|c|}
\hline Run & $\mathrm{R}_{\mathrm{a}}(\mu \mathrm{m})$ & S/N Ratio \\
\hline 1 & 4.71 & -13.46 \\
\hline 2 & 4.85 & -13.71 \\
\hline 3 & 5.02 & -14.01 \\
\hline 4 & 3.93 & -11.88 \\
\hline 5 & 3.99 & -12.01 \\
\hline 6 & 4.16 & -12.38 \\
\hline 7 & 4.01 & -12.06 \\
\hline 8 & 4.12 & -12.29 \\
\hline 9 & 4.24 & -12.54 \\
\hline
\end{tabular}

Table 7 Mean S/N response table for surface roughness for wet turning with water based fluid

\begin{tabular}{|c|c|c|c|}
\hline Level & Spindle speed & Feed rate & Depth of cut \\
\hline 1 & -13.73 & -12.47 & -12.71 \\
\hline 2 & -12.10 & -12.68 & -12.72 \\
\hline 3 & -12.30 & -12.98 & -12.70 \\
\hline Delta & 1.63 & 0.51 & 0.02 \\
\hline Rank & 1 & 2 & 3 \\
\hline
\end{tabular}

The main effect plots for surface roughness is given in figure 2, which shows that to reduce level of surface roughness, spindle speed should be set to its medium level, feed rate and depth of cut to their lowest and highest levels, respectively.

Table 8 shows the results of ANOVA for surface roughness obtained in wet turning with water based fluid.

Table 8 ANOVA table for surface roughness obtained in wet turning with water based fluid

\begin{tabular}{|c|c|c|c|c|}
\hline Source & DoF & Adj SS & p-value & $\% \mathrm{C}$ \\
\hline $\begin{array}{c}\text { Spindle } \\
\text { speed }\end{array}$ & 2 & 1.24 & 0.002 & 92.36 \\
\hline Feed rate & 2 & 0.10 & 0.028 & 7.41 \\
\hline Depth of cut & 2 & 0.0002 & 0.935 & 0.02 \\
\hline Error & 2 & 0.002 & - & 0.21 \\
\hline Total & 8 & 1.340 & - & - \\
\hline
\end{tabular}

From table 8, it is confirmed that spindle speed was the most significant factor which effected surface roughness having percentage contribution up to $92.36 \%$. After that, second influencing factor was feed rate having percentage contribution up to $7.41 \%$ and depth of cut had very little role to play on surface roughness. It is the same order of significance for the cutting parameters on surface roughness, which was observed in table 7 . The regression equation generated through the analysis is written as equation 2 .
Suraface roughness $=5.136-0.525$ Spindle Speed + 0.175 Feed Rate + 0.248 Depth of Cut

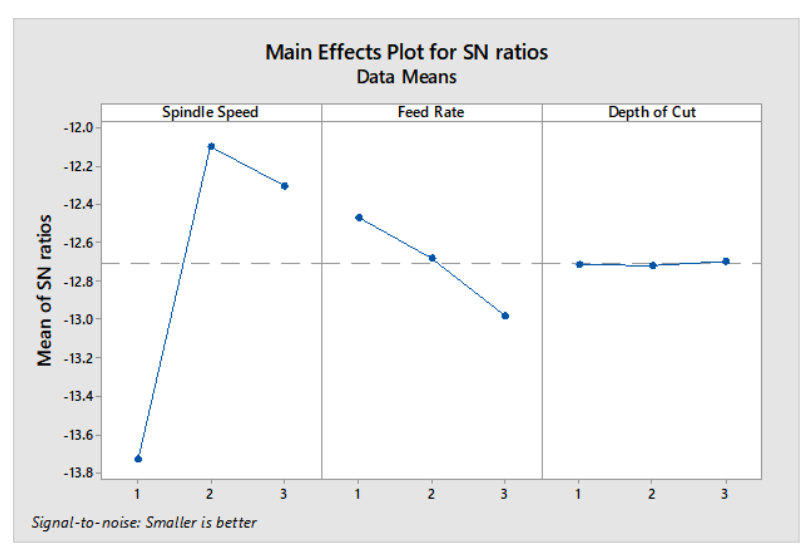

Fig. 2 The main effects plot for $\mathrm{S} / \mathrm{N}$ ratios of surface roughness for wet turning with water based fluid

\subsection{Wet Turning with Mineral oil as cutting Fluid}

The value of $\mathrm{S} / \mathrm{N}$ ratio for surface roughness for each experimental run is given in table 9. The mean $\mathrm{S} / \mathrm{N}$ response table for surface roughness is given as table 10 . From the table 10 , similarly to the wet turning with water based cutting fluid, spindle speed had greatest influence on surface roughness as well as in this case. Similarly, Feed rate was the second influencing factor followed by depth of cut in case of surface roughness in this case also. The main effect plot for surface roughness is given in figure 3 . It shows that in this case also to reduce level of surface roughness, spindle speed should be set to its medium level, feed rate and depth of cut to their lowest and highest level.

Table $9 \mathrm{~S} / \mathrm{N}$ ratio values of surface roughness for wet turning with mineral oil as cutting fluid

\begin{tabular}{|c|c|c|}
\hline Run & $\mathrm{R}_{\mathrm{a}}(\mu \mathrm{m})$ & S/N Ratio \\
\hline 1 & 4.79 & -13.60 \\
\hline 2 & 4.92 & -13.83 \\
\hline 3 & 5.13 & -14.20 \\
\hline 4 & 3.88 & -11.77 \\
\hline 5 & 3.95 & -11.93 \\
\hline 6 & 4.24 & -12.54 \\
\hline 7 & 3.77 & -11.52 \\
\hline 8 & 4.01 & -12.06 \\
\hline 9 & 4.41 & -12.88 \\
\hline
\end{tabular}

Table 10 Mean S/N response table of surface roughness for wet turning with mineral oil as cutting fluid

\begin{tabular}{|c|c|c|c|}
\hline Level & Spindle speed & Feed rate & $\begin{array}{c}\text { Depth of } \\
\text { cut }\end{array}$ \\
\hline 1 & -13.88 & -12.30 & -12.74 \\
\hline 2 & -12.09 & -12.61 & -12.83 \\
\hline 3 & -12.16 & -13.21 & -12.55 \\
\hline Delta & 1.80 & 0.91 & 0.28 \\
\hline Rank & 1 & 2 & 3 \\
\hline
\end{tabular}




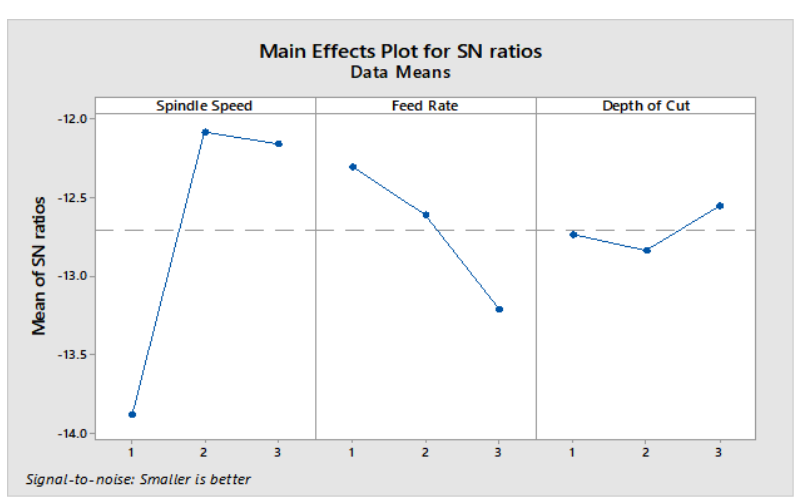

Fig. 3 The main effects plot for $\mathrm{S} / \mathrm{N}$ ratios of surface roughness for wet turning with mineral oil as cutting fluid

Table 11 shows the results of ANOVA for surface roughness. Table 11 confirms the results of table 10, i.e. spindle speed was the most significant factor which effected surface roughness having percentage contribution up to $82.74 \%$. After that, second influencing factor was feed rate having percentage contribution up to $15.74 \%$ and depth of cut had very little role to play on surface roughness. The regression equation generated through the analysis is written as equation 3.

Surface roughness $==4.807-0.368$ Spindle Speed + 0.128 Feed Rate + 0.005 Depth of Cut

Table 11 ANOVA table for surface roughness

\begin{tabular}{|c|c|c|c|c|}
\hline Source & DoF & Adj SS & p-value & $\% \mathrm{C}$ \\
\hline $\begin{array}{c}\text { Spindle } \\
\text { speed }\end{array}$ & 2 & 1.63 & 0.005 & 82.74 \\
\hline Feed rate & 2 & 0.31 & 0.026 & 15.74 \\
\hline $\begin{array}{c}\text { Depth of } \\
\text { cut }\end{array}$ & 2 & 0.02 & 0.274 & 1.09 \\
\hline Error & 2 & 0.008 & - & 0.43 \\
\hline Total & 8 & 1.98 & - & - \\
\hline
\end{tabular}

\subsection{Confirmation tests}

Conformation tests were performed taking the optimal levels of the given parameters for all the three cases. For case 1, i.e. dry turning the optimal levels of cutting parameters were spindle speed at level 3 , depth of cut and feed rate at level 1 . The experimental value of $R_{a}$ was found to be $4.34 \mu \mathrm{m}$ which is very close to 4.28 $\mu \mathrm{m}$ as predicted by equation 4.1 . For case 2 , i.e. wet turning with water based cutting fluid, the optimal levels of cutting parameters were spindle speed at level 2 , depth of cut at level 1 and feed rate at level 3. The experimental value of $R_{a}$ was found to be $4.03 \mu \mathrm{m}$ as predicted value was $3.98 \mu \mathrm{m}$ by equation 4.2 . For case 3 , i.e. wet turning with mineral oil as cutting fluid, the optimal levels of cutting parameters were spindle speed at level 2, depth of cut at level 1 and feed rate at level 3. The experimental value of $R_{a}$ was found to be $4.24 \mu \mathrm{m}$ as predicted value was $4.21 \mu \mathrm{m}$ by equation 4.3 .

\section{Conclusion}

This study has presented the application of Taguchi design of experiments and statistical method like S/N ratio analysis and ANOVA method for studying the effect of different cutting parameters on surface roughness during dry and wet turning of AISI 1020. In wet turning two different types of cutting fluids, namely water based cutting fluid and mineral oil were used. The following conclusions were drawn from from the experiment.

- In case of dry turning spindle speed (\%C 78\%) was the most significant factor which effected surface roughness. After that second influencing factor was depth of cut $(\% \mathrm{C} \sim 12 \%)$ followed by feed rate $(\% \mathrm{C} \sim 5 \%)$.

- In case of wet turning with water based cutting fluid spindle speed $(\% \mathrm{C} \sim 92 \%)$ was the most significant factor which effected surface roughness. After that second influencing factor was feed rate (\%C $\sim 7 \%)$ and depth of cut had very little role to play on surface roughness.

- In case of wet turning with mineral oil as cutting fluid spindle speed $(\% \mathrm{C} \sim 82 \%)$ was the most significant factor which effected surface roughness. After that second influencing factor was feed rate $(\% \mathrm{C} \sim 15 \%)$ and depth of cut had very little role to play on surface roughness.

For further study new factors like different tool geometry, fluid flow rate, workpiece materials could be considered, a new type of experimental design and statistical analysis could be used, no interaction of factors was considered in the experiment, and interactions could be considered using larger designs from experimental designs.

\section{References}

Abhang, L.B. and Hameedullah, M., 2014. Parametric investigation of turning process on en-31 steel. Procedia Materials Science, 6, pp.1516-1523.

Dornfeld, D.A.; Helu, M. Precision Manufacturing, First Edition, Springer Publishing: Midtown Manhattan, New York City, 2007.

Juneja, B.L.; Seth, N.; Sekhon, G.S. Fundamentals of Metal Cutting and Machine Tools, Second Edition, New Age Publications: Daryaganj, New Delhi, 2003.

Azam, M., Jahanzaib, M., Wasim, A. and Hussain, S., 2015. Surface roughness modeling using RSM for HSLA steel by coated carbide tools. The International Journal of Advanced Manufacturing Technology, 78(5-8), pp.10311041.

Khan, M.M.A., Mithu, M.A.H. and Dhar, N.R., 2009. Effects of minimum quantity lubrication on turning AISI 9310 alloy steel using vegetable oil-based cutting fluid. Journal of materials processing Technology, 209(15), pp.5573-5583.

Suresh, R., Basavarajappa, S. and Samuel, G.L., 2012. Some studies on hard turning of AISI 4340 steel using 
multilayer coated carbide tool Measurement, 45(7), pp.1872-1884.

Ciftci, I., 2006. Machining of austenitic stainless steels using CVD multi-layer coated cemented carbide tools. Tribology International, 39(6), pp.565-569.

Debnath, S., Reddy, M.M. and Yi, Q.S., 2016. Influence of cutting fluid conditions and cutting parameters on surface roughness and tool wear in turning process using Taguchi method. Measurement, 78, pp.111-119.
Dhiman, S., Sehgal, R., Sharma, S.K. and Sharma, V.S., 2008. Machining behavior of AlSI 1018 steel during turning. Journal of Scientific and Industrial Research, 67(5), p.355-361.

Patel, J.M. and Panchal, P., 2014, Parametric Analysis of Dry and Wet Turning on CNC Lathe using Design Of Experiment, International Journal For Technological Research In Engineering, 1(9), pp. 686-694. 